\title{
MS/MS studies on the selective on-line detection of sesquiterpenes using a Flowing Afterglow-Tandem Mass Spectrometer (FA-TMS)
}

\author{
J. Rimetz-Planchon ${ }^{1}$, F. Dhooghe ${ }^{1,2}$, N. Schoon ${ }^{1}$, F. Vanhaecke ${ }^{2}$, and C. Amelynck ${ }^{1}$ \\ ${ }^{1}$ Belgian Institute for Space Aeronomy, Ringlaan 3, 1180 Brussels, Belgium \\ ${ }^{2}$ Department of Analytical Chemistry, Ghent University, Krijgslaan 281, S12, 9000 Ghent, Belgium
}

Received: 3 September 2010 - Published in Atmos. Meas. Tech. Discuss.: 5 October 2010

Revised: 16 March 2011 - Accepted: 31 March 2011 - Published: 7 April 2011

\begin{abstract}
A Flowing Afterglow-Tandem Mass Spectrometer (FA-TMS) was used to investigate the feasibility of selective on-line detection of a series of seven sesquiterpenes (SQTs). These SQTs were chemically ionized by either $\mathrm{H}_{3} \mathrm{O}^{+}$or $\mathrm{NO}^{+}$reagent ions in the FA, resulting among others in protonated SQT and SQT molecular ions, respectively. These and other Chemical Ionization (CI) product ions were subsequently subjected to dissociation by collisions with Ar atoms in the collision cell of the tandem mass spectrometer. The fragmentation spectra show similarities with mass spectra obtained for these compounds with other instruments such as a Proton Transfer Reaction-Linear Ion Trap (PTR-LIT), a Proton Transfer Reaction-Mass Spectrometer (PTR-MS), a Triple Quadrupole-Mass Spectrometer (QqQ-MS) and a Selected Ion Flow Tube-Mass Spectrometer (SIFT-MS). Fragmentation of protonated SQT is characterized by fragment ions at the same masses but with different intensities for the individual SQT. Distinction of SQTs is based on well-chosen intensity ratios and collision energies. The fragmentation patterns of SQT molecular ions show specific fragment ion tracers at $\mathrm{m} / \mathrm{z} 119, \mathrm{~m} / \mathrm{z} 162, \mathrm{~m} / \mathrm{z} 137$ and $\mathrm{m} / \mathrm{z} 131$ for $\alpha$ cedrene, $\delta$-neoclovene, isolongifolene and $\alpha$-humulene, respectively. Consequently, chemical ionization of SQT by $\mathrm{NO}^{+}$, followed by MS/MS of $\mathrm{SQT}^{+}$seems to open a way for selective quantification of SQTs in mixtures.
\end{abstract}

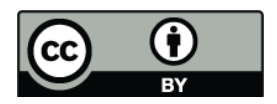

Correspondence to: C. Amelynck (crist.amelynck@aeronomie.be)

\section{Introduction}

Sesquiterpenes (SQTs) $\left(\mathrm{C}_{15} \mathrm{H}_{24}\right)$ are Biogenic Volatile Organic Compounds (BVOCs) composed of three isoprene units. They are biosynthesized by plants (Kesselmeier and Staudt, 1999; Loreto and Schnitzler, 2010) to attract flower pollinators (Pichersky and Gershenzon, 2002) and to cope with environmental stress conditions (Paré and Tumlinson, 1997, 1999). SQT emissions are globally lower than those of isoprene and monoterpenes (Kesselmeier and Staudt, 1999) and the emission rates depend on the vegetation species and biotic (e.g. phenological state of the plant, infestation, ...) and abiotic (e.g. temperature and light) factors (Duhl et al., 2008; Holopainen and Gershenzon, 2010; Loreto and Schnitzler, 2010).

The generally high reactivity (especially towards ozone) and the low vapor pressure make SQTs important actors in atmospheric chemistry and Secondary Organic Aerosol (SOA) formation. The atmospheric lifetime of SQTs against ozonolysis is typically a few minutes. A notable exception is longifolene, the lifetime of which is of the order of several days (Canosa-Mas et al., 1999; Atkinson and Arey, 2003). Experimentally determined SOA mass yields from the gasparticle partitioning of SQT oxidation products vary from 29 ( $\gamma$-caryophyllene) to $125 \%$ ( $\beta$-caryophyllene), depending on the SQT studied and the type of oxidant (Bonn and Moortgat, 2003; Lee et al., 2006a,b). Because of the different chemistry of individual SQT, it is necessary to measure the SQT isomers independently in order to better understand the individual impact of each SQT on atmospheric processes and air quality (i.e. tropospheric ozone and SOA formation), carbon cycle, and global change (Duhl et al., 2008; Peñuelas and Staudt, 2010). 
Because of their reactive nature and their low volatility, the accurate measurement of SQTs is not straightforward. Special care needs to be taken to avoid sampling and preconcentration artifacts when using conventional techniques based on gas chromatography (Helmig and Arey, 1992; Helmig et al., 2003; Bouvier-Brown et al., 2009). Due to the high sensitivity of Chemical Ionization Mass Spectrometry (CIMS) techniques, sampling problems are eliminated since the analysis can be carried out on-line without any need for preconcentration. Proton Transfer Reaction Mass Spectrometry (PTR-MS), a CIMS technique which uses $\mathrm{H}_{3} \mathrm{O}^{+}$reagent ions, was recently used for the measurement of total SQT emission rates at high sensitivity and time resolution (Ezra et al., 2004; Boy et al., 2008; Bouvier-Brown et al., 2009; Kim et al., 2009).

Despite its many interesting features, an important disadvantage of PTR-MS is its lack of selectivity (Blake et al., 2009). The most common PTR-MS instruments are quadrupole-based and only allow the separation of nominal ion masses. Even if the recent development of the high resolution Proton Transfer Reaction-Time of Flight-Mass Spectrometer (PTR-ToF-MS) (Blake et al., 2004; Jordan et al., 2009; Graus et al., 2010) opens the possibility of distinguishing nominally isobaric compounds on the basis of their accurate masses and with high sensitivity due to the absence of mass discrimination for higher mass ions, the distinction of isomers remains difficult. With such an instrument, Jordan et al. (2009) recently succeeded in measuring a few pptv of SQTs in urban air of Innsbruck (Austria) based on the signal at the exact mass-to-charge ratio $\mathrm{m} / \mathrm{z}$ of 205.1951, which corresponds with the protonated SQT $\left(\mathrm{C}_{15} \mathrm{H}^{+}\right)$, produced by the proton transfer reaction with $\mathrm{H}_{3} \mathrm{O}^{+}$reagent ions. In order to assist with SQT identification, MS techniques allowing Collision Induced Dissociation (CID) of CI product ions (MS/MS techniques) can be envisaged. Indeed, it has been shown that the intensities of the ions resulting from fragmentation processes occurring in a drift tube depend on the energy available (ratio of the electric field to the buffer gas number density, $E / N$ ) and the type of SQT (Demarcke et al., 2009; Kim et al., 2009). Consequently, the application of MS/MS techniques for the study of fragmentation schemes obtained under controlled conditions (pressure and nature of collision gas and collision energy) can be envisaged as a possibility to distinguish SQTs. Such fragmentation experiments were already performed in a Townsend Discharge Triple Quadrupole-Mass Spectrometer (QqQ-MS) and in a Proton Transfer Reaction-Linear Ion Trap (PTRLIT) by Müller et al. (2009) to distinguish $\alpha$-humulene from farnesene. These authors succeeded in differentiating these two SQTs based on the ratios of intensities of certain CID fragment ions, $I_{m / z}$, more particularly $I_{149} / I_{121}$ and $I_{93} / I_{81}$. This interesting work needs to be completed by taking into account other SQTs and a range of collision energies. A part of the present study deals with the fragmentation of CI product ions, resulting from the interaction of $\mathrm{H}_{3} \mathrm{O}^{+}$reagent ions with seven SQTs, in a Flowing Afterglow-Tandem Mass Spectrometer (FA-TMS) at different collision energies. This instrument, previously used to investigate the feasibility of such a technique for the selective detection of five C5 unsaturated alcohols and isoprene (Rimetz-Planchon et al., 2010), has been optimized for the study of SQTs.

Müller et al. (2009) showed that the fragmentation of protonated $\alpha$-humulene and farnesene resulted in different intensities of fragment ions but not in different $\mathrm{m} / \mathrm{z}$ values for these fragments. Furthermore, no specific SQT fragment ions were found by Selected Ion Flow Tube-Mass Spectrometry (SIFT-MS) (Dhooghe et al., 2008) or PTR-MS with $\mathrm{H}_{3} \mathrm{O}^{+}$as reagent ion (Demarcke et al., 2009; Kim et al., 2009). A further possible improvement of MS/MS techniques in order to succeed in monitoring one SQT in a mixture of several SQTs could be the use of a different reagent ion such as $\mathrm{NO}^{+}$. This ion species was already used as CI reagent ion to distinguish isobaric and even isomeric compounds. Soft ionization of analyte molecules by $\mathrm{NO}^{+}$can proceed via multiple reaction mechanisms, such as association, charge and hydride ion transfer, possibly followed by fragmentation. A large library of reaction rates and product ion distributions of the reaction of $\mathrm{NO}^{+}$ions with many VOCs of different chemical functionalities has been built up during the last fifteen years, mainly by Špaňel and Smith, in support of the detection of these compounds by SIFT-MS (Špaňel et al., 1997; Špaňel and Smith, 1997, 1998; Smith and Špaňel, 2005). Dhooghe et al. (2008) studied the product ion distribution from the CI of SQT by $\mathrm{NO}^{+}$in a SIFT-MS. In addition to the main SQT molecular ion at $\mathrm{m} / z, 204$ resulting from charge transfer, the authors observed some specific SQT fragment ions.

Recently $\mathrm{NO}^{+}$reactant ions have also been used in medium-pressure (a few mbar) drift tube instrumentation. Wyche et al. (2005) investigated the detection of some alkenes, aromatic hydrocarbons, alcohols, aldehydes, ketones, nitriles and esters in a drift tube reactor coupled to a reflectron time-of-flight mass spectrometer (Wyche et al., 2005; Blake et al., 2006), and Knighton et al. (2009) succeeded in detecting 1,3-butadiene by employing a commercial PTR-MS in $\mathrm{NO}^{+}$mode. Moreover, a highly sensitive Proton Transfer Reaction-Switchable Reagent Ion-Mass Spectrometer (PTR-SRI-MS) instrument which enables the use of $\mathrm{H}_{3} \mathrm{O}^{+}, \mathrm{NO}^{+}$and $\mathrm{O}_{2}^{-+}$ions (Jordan et al., 2009) has recently become commercially available (Ionicon Analytik $\mathrm{GmbH}$, Innsbruck, Austria). Even if $\mathrm{CI}$ by $\mathrm{NO}^{+}$seems to be a good approach to distinguish SQTs, Wyche et al. (2005) stated that it cannot be used routinely in a PTR-MS instrument for detection and quantification of VOCs in mixtures. Indeed, the greater degree of fragmentation that they observed with $\mathrm{NO}^{+}$as reagent ions (compared to $\mathrm{CI}$ by $\mathrm{H}_{3} \mathrm{O}^{+}$) causes spectral interference. Moreover, it is expected that at ambient measurements isobaric interferences of oxygenated species are very likely when using $\mathrm{NO}^{+}$reactant ions. The use of FA-TMS with $\mathrm{NO}^{+}$as $\mathrm{CI}$ reagent ion can possibly prevent this problem, since fragmentation is performed on a $\mathrm{CI}$ 


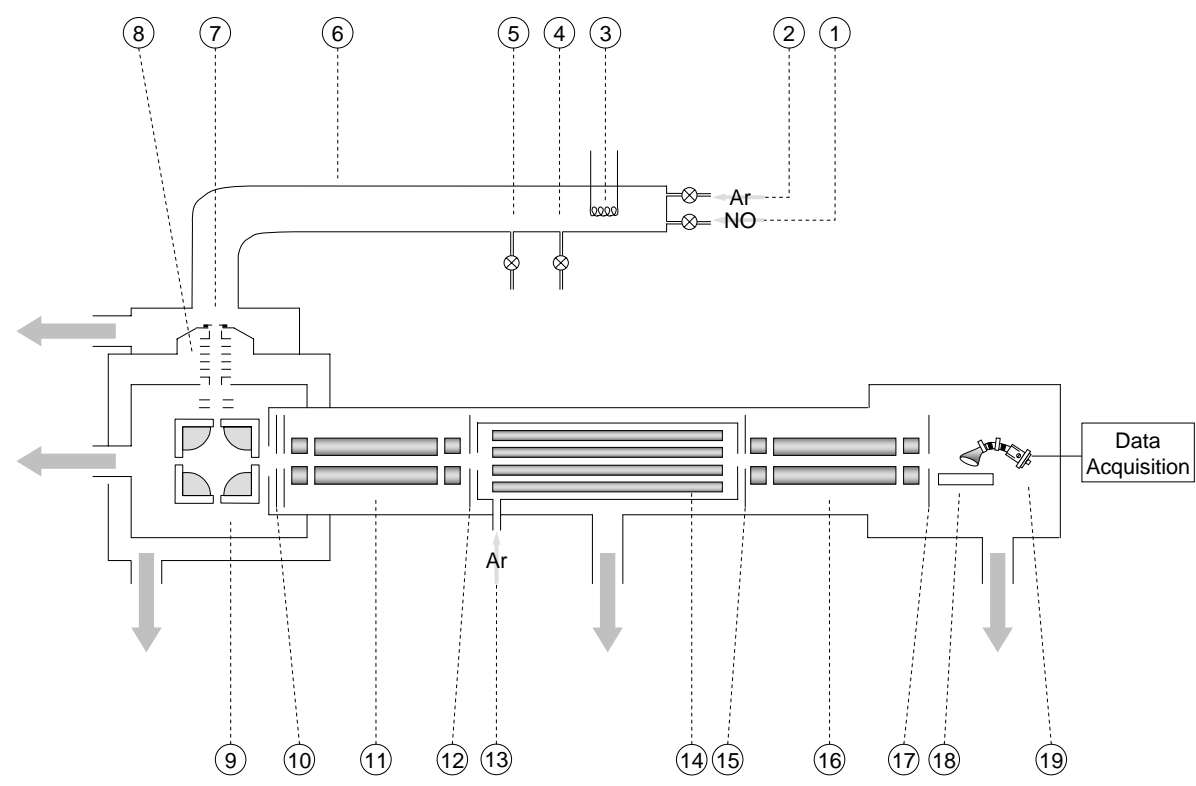

Fig. 1. Schematic representation of the FA-TMS instrument. Light grey arrows indicate regulated gas flows entering the instrument, dark grey arrows indicate gas flows exiting the instrument towards the pumping systems. (1) NO inlet, (2) Argon inlet, (3) electron emitting filament, (4-5) neutral inlets $\left(\mathrm{H}_{2} \mathrm{O}\right.$, SQT), (6) flow tube (FT), (7) interface plate, (8) lens system, (9) ion deflector, (10) entrance lens to first quadrupole, (11) first quadrupole with pre- and post filter, (12) lens between first quadrupole and octupole, (13) argon collision gas inlet, (14) octupole collision cell, (15) lens between octupole and second quadrupole, (16) second quadrupole with pre- and post filter, (17) exit lens, (18) discrete dynode, (19) electron multiplier.

product ion isolated from the complex matrix present in the FA. Another part of the present work is therefore dedicated to the study of the fragmentation of ions produced by the reaction with $\mathrm{NO}^{+}$, in order to find tracer ions, which could be used for the detection and the quantification of SQTs in mixtures. Determination of tracer ions was based on fragmentation patterns of protonated SQTs at $\mathrm{m} / z 204$. Application to atmospheric samples states that isobaric interferences at this mass-to-charge ratio are limited.

\section{Materials and methods}

\subsection{FA-TMS}

The FA-TMS consists of a home-made Flowing Afterglow reactor, which is coupled to a Tandem Mass Spectrometer, custom-designed by Extrel CMS (Pittsburgh, USA). A schematic representation of the instrument is given in Fig. 1. The instrument has already been thoroughly described in a previous paper (Rimetz-Planchon et al., 2010) and will only be briefly discussed here. The reaction between a SQT and a reagent ion $\left(\mathrm{NO}^{+}\right.$or $\left.\mathrm{H}_{3} \mathrm{O}^{+}\right)$takes place in the FA. The resulting CI product ions are sampled into the TMS. The $\mathrm{CI}$ product ion of interest, also called precursor ion, is selected by a first quadrupole and enters the octupole collision cell, which is filled with the collision gas (Ar) at a pressure of $0.11 \mathrm{~Pa}$. This pressure was chosen to have a sufficiently high fragmentation yield. Depending on the collision energy in the center-of-mass frame $\left(E_{\mathrm{CM}}\right)$, controlled by the pole bias of the octupole, one or more fragments will be produced. The fragmentation spectrum is obtained by performing a mass scan with the second quadrupole and the ions are detected with a secondary electron multiplier, operating in pulse counting mode.

The two main adaptations of the instrument needed for the present study concern the introduction system of SQTs and the production of $\mathrm{NO}^{+}$in the FA. Due to the low vapor pressure and the sticky nature of SQT, a static mixture of SQT vapor in an inert gas is instable. Thus SQTs are introduced dynamically in the FA by blowing a controlled small flow of argon gas over a reservoir filled with the pure liquid SQT. The temperature of the liquid is kept constant at $279 \mathrm{~K}$ by immersing the reservoir in a thermostatically controlled water bath and all stainless steel tubing between the reservoir and the flow tube is heated to avoid SQT deposition. The SQT flow that enters the reactor is regulated by varying the pressure above the reservoir by means of a needle valve located between the reservoir and the flow tube.

The reagent ions $\mathrm{NO}^{+}$are created upstream the flow tube by the impact of electrons emitted by a thoriated iridium filament onto NO. The ionization energy of $\mathrm{NO}^{\bullet}(9.26 \mathrm{eV})$ is lower than that of $\operatorname{Ar}(15.76 \mathrm{eV})$, the flowing afterglow buffer gas, and therefore the voltage of the counter-electrode, which determines the energy of the electrons has been lowered to favor the ionization of $\mathrm{NO}^{\bullet}$. 
<smiles>C=C1C2CCCC1(C)C1CCCC2(C)C1(C)C</smiles>

Longifolene<smiles>CC1(C)C=CCC2=C1CCCC2(C)C</smiles>

Isolongifolene

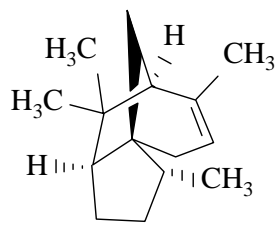

$\alpha$-cedrene<smiles>CC1CC=C[C@]2(C)[C@H]1C=CC2(C)C</smiles>

$\delta$-neoclovene<smiles>C=C1CC[C@@H]2[C@H]([C@@H]3C1CC[C@@H]3C)C2(C)C</smiles>

Aromadendrene

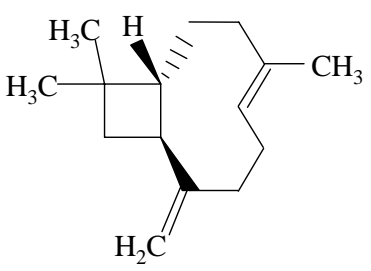

$\beta$-caryophyllene<smiles>CC1=CCC(C)=CCC(C)(C)C=CC1</smiles>

$\alpha$-humulene

Fig. 2. Molecular structures of the seven sesquiterpenes studied.

\subsection{Data acquisition}

Measurements were performed with seven SQTs: aromadendrene, $\beta$-caryophyllene, $\alpha$-cedrene, $\alpha$-humulene, isolongifolene, longifolene and $\delta$-neoclovene, the structures of which are given in Fig. 2.

Mass spectra of fragment and precursor ions were acquired for different $E_{\mathrm{CM}}$ values. The calculation of $E_{\mathrm{CM}}$ requires the determination of the stopping potential, obtained by retardation potential analysis (Rimetz-Planchon et al., 2010). The mean stopping potential and the spread of the precursor ions are $-3.8 \mathrm{~V} \pm 0.1 \mathrm{~V}$ and $1.7 \mathrm{~V} \pm 0.1 \mathrm{~V}$ Full Width at Half Maximum (FWHM), respectively. The FWHM is higher than observed in other TMS instruments (Muntean and Armentrout, 2001), but sufficient for our purposes. For each fragment, the plot of intensity as a function of $E_{\mathrm{CM}}$ is called appearance curve.

The range of $E_{\mathrm{CM}}$ was $0.6-8 \mathrm{eV}$. For $E_{\mathrm{CM}}>8 \mathrm{eV}$, scattering and defocusing effects became too important, as characterized by a decrease of more than $50 \%$ of the maximum collection efficiency $\left(E_{\mathrm{c}}\right)$ value (Fig. 3 and Eq. 1 ) and deformed peaks. For $E_{\mathrm{CM}}<0.6 \mathrm{eV}$, the uncertainty on the intensity of fragment ions was too high to exploit fragmentation data.

The values of collection $\left(E_{\mathrm{c}}\right)$, fragmentation $\left(E_{\mathrm{f}}\right)$ and CID $\left(E_{\mathrm{CID}}\right)$ efficiencies for the fragmentation of each protonated SQT and SQT molecular ions were calculated as follows (Yost et al., 1979; Thomson et al., 1995; Ibrahim et al., 2010):

$$
\begin{aligned}
& E_{\mathrm{c}}(\%)=100 \times \frac{I_{\mathrm{p}}+\sum_{i} I_{\mathrm{fi}}}{I_{\mathrm{p} 0}} \\
& E_{\mathrm{f}}(\%)=100 \times \frac{\sum_{i} I_{\mathrm{fi}}}{I_{\mathrm{p}}+\sum_{i} I_{\mathrm{fi}}}
\end{aligned}
$$

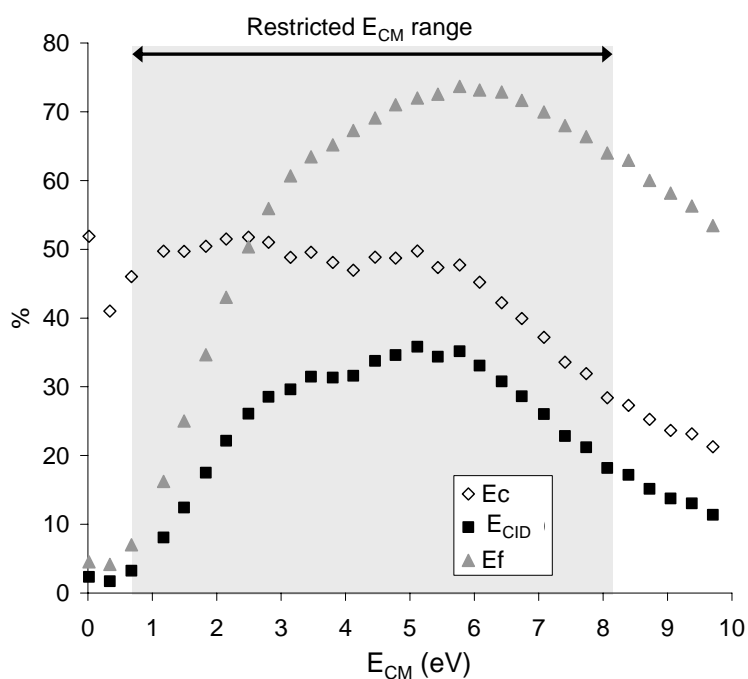

Fig. 3. Collection $\left(E_{\mathrm{c}}\right)$, fragmentation $\left(E_{\mathrm{f}}\right)$ and CID $\left(E_{\mathrm{CID}}\right)$ efficiencies (in \%) as a function of collision energy $\left(E_{\mathrm{CM}}\right)$ for the fragmentation of protonated $\alpha$-cedrene. The restricted $E_{\mathrm{CM}}$ range considered in this study is indicated.

$E_{\mathrm{CID}}(\%)=100 \times \frac{\sum_{i} I_{\mathrm{fi}}}{I_{\mathrm{p} 0}}$

where $I_{\mathrm{p}}$ is the intensity of the precursor ion, $I_{\mathrm{f}}$, the intensity of the fragment ion fi, and $I_{\mathrm{p} 0}$, the intensity of the precursor ion when no collision gas is introduced in the collision cell. $E_{\mathrm{c}}$ is influenced by scattering effects, whereas $E_{\mathrm{f}}$ represents the efficiency of producing fragment ions. $E_{\mathrm{CID}}$ reflects these two combined effects (Ibrahim et al., 2010). $E_{\mathrm{c}}, E_{\mathrm{f}}$ and $E_{\mathrm{CID}}$ values are similar for the SQTs studied. An example is shown for $\alpha$-cedrene (Fig. 3). Values of $E_{\mathrm{c}}$ range from about 22 to $54 \%$ and from 27 to $95 \%$ for the fragmentation of protonated 
SQT and SQT molecular ions, respectively. Best values are found for $E_{\mathrm{CM}}$ values between 1.2 and $5.4 \mathrm{eV}$. Scattering increases strongly for collision energies above about $6 \mathrm{eV}$. Values of $E_{\mathrm{f}}$ range from about 5 to $76 \%$ and from 5 to $84 \%$ for the fragmentation of protonated SQT and SQT molecular ions, respectively. Best values are found for $E_{\mathrm{CM}}$ values between 5 and $6 \mathrm{eV}$. Values of $E_{\mathrm{CID}}$ vary between 2 and $40 \%$ and 2 to $41 \%$ for the fragmentation of protonated SQT and SQT molecular ions, respectively. Best values are found for $E_{\mathrm{CM}}$ values around $5 \mathrm{eV}$.

In order to compare the fragmentation patterns of the different SQTs, the intensity of each fragment is expressed in percentage relative to the sum of intensities of all fragments, which is called fragmentation fraction. In what follows, the Maximum Fragmentation Fraction (MFF) refers to the maximum value found along the collision energy range.

\subsection{Chemical}

Aromadendrene (97\%), isolongifolene (98\%), $\alpha$-humulene (98\%), $\delta$-neoclovene (98\%), $\beta$-caryophyllene (98.5\%), longifolene (99\%) and $\alpha$-cedrene (99\%) were purchased from Fluka. Argon (99.9997\%), $\mathrm{SF}_{6}(1000 \mathrm{ppmv}$ in Ar) and $\mathrm{NO}^{\bullet}(5 \%$ in $\mathrm{He})$ were obtained from Air Products.

\section{Results and discussion}

The fragmentation of protonated SQT $(\mathrm{m} / z, 205)$ and SQT molecular ions $(\mathrm{m} / \mathrm{z}, 204)$ were studied for each of the seven SQTs. The list of resulting fragment ions is presented in Table 1. The fragmentation rules are respected (de Hoffman and Stroobant, 2007) as expected: the even-electrons cations $\left(\mathrm{EE}^{+}\right)$at $\mathrm{m} / \mathrm{z} 205$ do not fragment into odd-electrons cations $\left(\mathrm{OE}^{+}\right)$, also called radical cations, but only into $\mathrm{EE}^{+}$, since the fragmentation of $\mathrm{EE}^{+}$into $\mathrm{OE}^{\bullet+}$ is an endothermic and thus, improbable reaction. The $\mathrm{OE}^{\bullet+}$ at $m / z 204$ fragment into both $\mathrm{OE}^{\bullet+}$ and $\mathrm{EE}^{+}$. Depending on the type of fragmentation, neutral losses under the form of molecules or radicals can occur.

\subsection{Fragmentation patterns of protonated SQT $(m / z, 205)$}

The $\mathrm{EE}^{+}$fragments from the fragmentation of protonated SQT were classified into five families (A to E), which each gather fragments separated by a $\mathrm{CH}_{2}$ unit $(14 \mathrm{u})$, according to the previous classification used by Dhooghe et al. (2008) and Demarcke et al. (2009) (Table 1). Dhooghe et al. (2008) determined the product ion distributions from the reactions between $\mathrm{H}_{3} \mathrm{O}^{+}$and the seven studied SQTs in a SIFT-MS at thermal conditions in a He buffer gas, corresponding to an estimated collision energy of $0.04 \mathrm{eV}$. Demarcke et al. (2009) studied the influence of the ratio $E / N$ on the product ion patterns from the reactions between $\mathrm{H}_{3} \mathrm{O}^{+}\left(\mathrm{H}_{2} \mathrm{O}\right) n(n=0$ to 2$)$ and four SQTs ( $\alpha$-humulene, $\alpha$-cedrene, longifolene and $\beta$ caryophyllene) in a PTR-MS at estimated collision energies ranging from 0.1 to $0.3 \mathrm{eV}$. These higher $E_{\mathrm{CM}}$ values (compared to the value in the SIFT-MS instrument) are due to additional translational energy of the ions caused by the presence of the drift field (Blake et al., 2009). The fact that higher collision energies are used in the TMS compared to those in SIFT-MS or PTR-MS explains why Dhooghe et al. (2008) and Demarcke et al. (2009) only observed fragment ions included in the families B and C (Table 1). Kim et al. (2009) and Ezra et al. (2004) also observed fragment ions of these two families by PTR-MS for $\beta$-caryophyllene, $\alpha$ humulene and aromadendrene and for $\alpha$-humulene, respectively (Table 1). Lee et al. (2006a) studied the patterns of ions produced by the reaction between $\mathrm{H}_{3} \mathrm{O}^{+}$and four SQTs ( $\beta$-caryophyllene, $\alpha$-humulene, longifolene and aromadendrene) in a PTR-MS. The authors found fragment ions included in the five families (Table 1). Most of the major fragment ions $(\mathrm{m} / \mathrm{z}, 135, \mathrm{~m} / \mathrm{z}, 149, \mathrm{~m} / \mathrm{z} 163, \mathrm{~m} / \mathrm{z}$ 95, $\mathrm{m} / \mathrm{z} 109$ and $m / z$ 123) observed in SIFT-MS (Dhooghe et al., 2008) and PTR-MS (Demarcke et al., 2009) instruments are also formed in the collision cell of the FA-TMS at collision energies below $2 \mathrm{eV}$ and with fragmentation fractions of at least $6 \%$, which shows that fragmentation patterns of SQTs are generally coherent between the three techniques. It needs to be stressed, however, that one should be cautious when comparing quantitatively branching ratios obtained by FA-TMS with those obtained by PTR-MS and SIFT-MS since mass discrimination of the FA-TMS instrument is not known.

Müller et al. (2009) studied the fragmentation of the protonated $\alpha$-humulene in the collision cell of a QqQ-MS instrument and in the ion trap of a PTR-LIT instrument. The authors present results for two collision cell offset voltages $\left(U_{\mathrm{cc}}=12 \mathrm{~V}\right.$ and $33 \mathrm{~V}$, Fig. $4 \mathrm{a}$ and $\left.\mathrm{b}\right)$ and one dipolar excitation voltage $\left(U_{\mathrm{CID}, \mathrm{PTR}-\mathrm{LIT}}=0.13 \mathrm{~V}\right.$, Fig. $\left.4 \mathrm{c}\right)$ for QqQ-MS and PTRLIT, respectively. Since these voltages were not converted in collision energies in the center-of-mass frame, we decided to choose three $E_{\mathrm{CM}}$ values in order to compare our results with those of Müller et al. (2009): (i) $0.68 \mathrm{eV}$ is the energy for which ions at $\mathrm{m} / \mathrm{z} 149$ reach their maximum fragmentation fraction in the collision energy range selected (Fig. 4c); (ii) $5.1 \mathrm{eV}$ is the energy for which $E_{\mathrm{CID}}$ (Eq. 3) is maximum (Fig. 4d); and (iii) $6.4 \mathrm{eV}$ is the energy for which ions at $\mathrm{m} / \mathrm{z} 81$ have their maximum fragmentation fraction (Fig. 4e). Although the results were not corrected for mass discrimination, spectra obtained by PTR-LIT, QqQ-MS at $12 \mathrm{~V}\left(U_{\mathrm{cc}}\right)$ and FA-TMS at $0.68 \mathrm{eV}$ are remarkably similar.

\subsection{Fragmentation pattern of SQT molecular ions $(m / z, 204)$}

The $\mathrm{EE}^{+}$and $\mathrm{OE}^{\bullet+}$ fragments from the fragmentation of SQT molecular ions were classified into six (A to F) and five (a to e) families, respectively (Table 1). The detailed fragmentation patterns for the individual SQT are presented 
Table 1. Families of fragments from the fragmentation of $\mathrm{m} / \mathrm{z}, 205$ and $\mathrm{m} / \mathrm{z}$ 204. In bold: fragment ions with a maximum fragmentation fraction $>10 \%$. For the fragmentation of ions at $m / z, 204, \mathrm{EE}^{+}$and $\mathrm{OE}^{\bullet+}$ fragments are distinguished.

\begin{tabular}{|c|c|c|c|c|c|c|c|c|c|c|c|}
\hline \multicolumn{12}{|c|}{ Fragmentation of protonated SQT $(\mathrm{m} / z$ 205) } \\
\hline \multicolumn{2}{|r|}{ A } & \multicolumn{2}{|c|}{$\mathrm{B}$} & \multicolumn{2}{|c|}{$\mathrm{C}$} & \multicolumn{2}{|c|}{$\mathrm{D}$} & \multicolumn{2}{|r|}{ E } & & \\
\hline $\begin{array}{l}77 \\
91 \\
105 \\
119 \\
133^{3} \\
147^{3} \\
161\end{array}$ & $\begin{array}{l}\mathrm{C}_{6} \mathrm{H}_{5}^{+} \\
\mathrm{C}_{7} \mathrm{H}_{7}^{+} \\
\mathrm{C}_{8} \mathrm{H}_{9}^{+} \\
\mathrm{C}_{9} \mathrm{H}_{11}^{+} \\
\mathrm{C}_{10} \mathrm{H}_{13}^{+} \\
\mathrm{C}_{11} \mathrm{H}_{15}^{+} \\
\mathrm{C}_{12} \mathrm{H}_{17}^{+}\end{array}$ & $\begin{array}{l}79 \\
\mathbf{9 3}^{2,5} \\
\mathbf{1 0 7}^{2} \\
\mathbf{1 2 1}^{1,2,3} \\
\mathbf{1 3 5}^{1,2,3,4,5} \\
\mathbf{1 4 9}^{1,2,3,4,5} \\
\mathbf{1 6 3}^{2,3} \\
177^{3} \\
\end{array}$ & $\begin{array}{l}\mathrm{C}_{6} \mathrm{H}_{7}^{+} \\
\mathrm{C}_{7} \mathrm{H}_{9}^{+} \\
\mathrm{C}_{8} \mathrm{H}_{11}^{+} \\
\mathrm{C}_{9} \mathrm{H}_{13}^{+} \\
\mathrm{C}_{10} \mathrm{H}_{15}^{+} \\
\mathrm{C}_{11} \mathrm{H}_{17}^{+} \\
\mathrm{C}_{12} \mathrm{H}_{19}^{+} \\
\mathrm{C}_{13} \mathrm{H}_{21}^{+} \\
\end{array}$ & $\begin{array}{l}67^{3} \\
\mathbf{8 1}^{1,2,3,4,5} \\
\mathbf{9 5}^{1,2,3,4} \\
\mathbf{1 0 9}^{1,2,3,4,5} \\
\mathbf{1 2 3}^{1,2,3,4,5} \\
137^{1,2,3,4}\end{array}$ & $\begin{array}{l}\mathrm{C}_{5} \mathrm{H}_{7}^{+} \\
\mathrm{C}_{6} \mathrm{H}_{9}^{+} \\
\mathrm{C}_{7} \mathrm{H}_{11}^{+} \\
\mathrm{C}_{8} \mathrm{H}_{13}^{+} \\
\mathrm{C}_{9} \mathrm{H}_{15}^{+} \\
\mathrm{C}_{10} \mathrm{H}_{17}^{+}\end{array}$ & $\begin{array}{l}41 \\
\mathbf{5 5} \\
\mathbf{6 9}^{3} \\
\mathbf{8 3}^{3} \\
97^{3} \\
111 \\
125^{3}\end{array}$ & $\begin{array}{l}\mathrm{C}_{3} \mathrm{H}_{5}^{+} \\
\mathrm{C}_{4} \mathrm{H}_{7}^{+} \\
\mathrm{C}_{5} \mathrm{H}_{9}^{+} \\
\mathrm{C}_{6} \mathrm{H}_{11}^{+} \\
\mathrm{C}_{7} \mathrm{H}_{13}^{+} \\
\mathrm{C}_{8} \mathrm{H}_{15}^{+} \\
\mathrm{C}_{9} \mathrm{H}_{17}^{+}\end{array}$ & $\begin{array}{l}29 \\
43 \\
57^{3} \\
71^{3} \\
85^{3}\end{array}$ & $\begin{array}{l}\mathrm{C}_{5} \mathrm{H}_{5}^{+} \\
\mathrm{C}_{3} \mathrm{H}_{7}^{+} \\
\mathrm{C}_{4} \mathrm{H}_{9}^{+} \\
\mathrm{C}_{5} \mathrm{H}_{11}^{+} \\
\mathrm{C}_{6} \mathrm{H}_{13}^{+}\end{array}$ & & \\
\hline \multicolumn{12}{|c|}{ Fragmentation of SQT molecular ions $(m / z, 204)-\mathrm{EE}^{+}$fragments } \\
\hline & A & B & & C & & & D & & $\mathrm{E}$ & & $\mathrm{F}$ \\
\hline $\begin{array}{l}77 \\
91 \\
105 \\
119 \\
133 \\
147^{1} \\
161^{1} \\
175 \\
189^{1}\end{array}$ & $\begin{array}{l}\mathrm{C}_{6} \mathrm{H}_{5}^{+} \\
\mathrm{C}_{7} \mathrm{H}_{7}^{+} \\
\mathrm{C}_{8} \mathrm{H}_{9}^{+} \\
\mathrm{C}_{9} \mathrm{H}_{11}^{+} \\
\mathrm{C}_{10} \mathrm{H}_{13}^{+} \\
\mathrm{C}_{11} \mathrm{H}_{15}^{+} \\
\mathrm{C}_{12} \mathrm{H}_{17}^{+} \\
\mathrm{C}_{13} \mathrm{H}_{19}^{+} \\
\mathrm{C}_{14} \mathrm{H}_{21}^{+}\end{array}$ & $\begin{array}{l}65 \\
79 \\
93 \\
107 \\
\mathbf{1 2 1} \\
135 \\
149\end{array}$ & $\begin{array}{l}\mathrm{C}_{5} \mathrm{H}_{5}^{+} \\
\mathrm{C}_{6} \mathrm{H}_{7}^{+} \\
\mathrm{C}_{7} \mathrm{H}_{9}^{+} \\
\mathrm{C}_{8} \mathrm{H}_{11}^{+} \\
\mathrm{C}_{9} \mathrm{H}_{13}^{+} \\
\mathrm{C}_{10} \mathrm{H}_{15}^{+} \\
\mathrm{C}_{11} \mathrm{H}_{17}^{+}\end{array}$ & $\begin{array}{l}67 \\
81 \\
95 \\
109 \\
123 \\
137\end{array}$ & $\begin{array}{l}\mathrm{C}_{5} \mathrm{H}_{7}^{+} \\
\mathrm{C}_{6} \mathrm{H}_{9}^{+} \\
\mathrm{C}_{7} \mathrm{H}_{11}^{+} \\
\mathrm{C}_{8} \mathrm{H}_{13}^{+} \\
\mathrm{C}_{9} \mathrm{H}_{15}^{+} \\
\mathrm{C}_{10} \mathrm{H}_{17}^{+}\end{array}$ & $\begin{array}{l}41 \\
55 \\
69 \\
83 \\
97 \\
111\end{array}$ & $\begin{array}{l}\mathrm{C}_{3} \mathrm{H}_{5}^{+} \\
\mathrm{C}_{4} \mathrm{H}_{7}^{+} \\
\mathrm{C}_{5} \mathrm{H}_{9}^{+} \\
\mathrm{C}_{6} \mathrm{H}_{11}^{+} \\
\mathrm{C}_{7} \mathrm{H}_{13}^{+1} \\
\mathrm{C}_{8} \mathrm{H}_{15}^{+}\end{array}$ & $\begin{array}{l}29 \\
43 \\
57 \\
71 \\
85\end{array}$ & $\begin{array}{l}\mathrm{C}_{5} \mathrm{H}_{5}^{+} \\
\mathrm{C}_{3} \mathrm{H}_{7}^{+} \\
\mathrm{C}_{4} \mathrm{H}_{9}^{+} \\
\mathrm{C}_{5} \mathrm{H}_{11}^{+} \\
\mathrm{C}_{6} \mathrm{H}_{13}^{+}\end{array}$ & $\begin{array}{l}131 \\
145\end{array}$ & $\begin{array}{l}\mathrm{C}_{10} \mathrm{H}_{11}^{+} \\
\mathrm{C}_{11} \mathrm{H}_{13}^{+}\end{array}$ \\
\hline \multicolumn{12}{|c|}{ Fragmentation of SQT molecular ions $(\mathrm{m} / z, 204)-\mathrm{OE}^{\bullet+}$ fragments } \\
\hline & A & B & & C & & & D & & $\mathrm{E}$ & & \\
\hline 118 & $\mathrm{C}_{9} \mathrm{H}_{10}^{\bullet+}$ & $\begin{array}{l}92 \\
106 \\
\mathbf{1 2 0} \\
134^{1} \\
\mathbf{1 4 8}^{1} \\
\mathbf{1 6 2}^{1} \\
176^{1}\end{array}$ & $\begin{array}{l}\mathrm{C}_{7} \mathrm{H}_{8}^{\bullet+} \\
\mathrm{C}_{8} \mathrm{H}_{10}^{\bullet+} \\
\mathrm{C}_{9} \mathrm{H}_{12}^{\bullet+} \\
\mathrm{C}_{10} \mathrm{H}_{14}^{\bullet+} \\
\mathrm{C}_{11} \mathrm{H}_{16}^{\bullet++} \\
\mathrm{C}_{12} \mathrm{H}_{18}^{\bullet+}+ \\
\mathrm{C}_{13} \mathrm{H}_{20}^{\bullet+}\end{array}$ & \begin{tabular}{l|l}
$80^{1}$ \\
$\mathbf{9 4}$ \\
$\mathbf{1 0 8}$ \\
$\mathbf{1 2 2}$ \\
136
\end{tabular} & $\begin{array}{l}\mathrm{C}_{6} \mathrm{H}_{8}^{\bullet+} \\
\mathrm{C}_{7} \mathrm{H}_{10}^{\bullet+} \\
\mathrm{C}_{8} \mathrm{H}_{12}^{\bullet+} \\
\mathrm{C}_{9} \mathrm{H}_{14}^{\bullet+} \\
\mathrm{C}_{10} \mathrm{H}_{16}^{\bullet+}\end{array}$ & $\begin{array}{l}82 \\
96 \\
110\end{array}$ & $\begin{array}{l}\mathrm{C}_{6} \mathrm{H}_{10}^{\bullet+} \\
\mathrm{C}_{7} \mathrm{H}_{12}^{\bullet+} \\
\mathrm{C}_{8} \mathrm{H}_{14}^{\bullet+}\end{array}$ & $\begin{array}{l}42 \\
56 \\
70\end{array}$ & $\begin{array}{l}\mathrm{C}_{3} \mathrm{H}_{6}^{\bullet+} \\
\mathrm{C}_{4} \mathrm{H}_{8}^{\bullet+} \\
\mathrm{C}_{5} \mathrm{H}_{10}^{\bullet+} \\
\mathrm{C}_{7} \mathrm{H}_{14}^{\bullet+}\end{array}$ & & \\
\hline
\end{tabular}

1 observed by Dhooghe et al. (2008); ${ }^{2}$ observed by Demarcke et al. (2009); ${ }^{3}$ observed by Lee et al. (2006a); ${ }^{4}$ observed by Kim et al. (2009); and ${ }^{5}$ observed by Ezra et al. (2004).

in Table 2. To our knowledge, CI of SQT by $\mathrm{NO}^{+}$followed by CID of the resulting $\mathrm{SQT}^{\bullet+}$ molecular ions was never performed up to now. The only data available for comparison concern the determination of the product ion distributions of the reactions between $\mathrm{NO}^{+}$and the SQT in a
SIFT-MS at low collision energy (Dhooghe et al., 2008) and Electron Impact (EI) spectra at high collision energy $(70 \mathrm{eV})$ (NIST database). Except for the ions at $\mathrm{m} / \mathrm{z} 80, \mathrm{~m} / \mathrm{z} 134$ and $m / z 176$ from $\beta$-caryophyllene, $\mathrm{NO}^{+} / \mathrm{SQT}$ product ions with yields $>2 \%$, as observed by Dhooghe et al. (2008), are also 

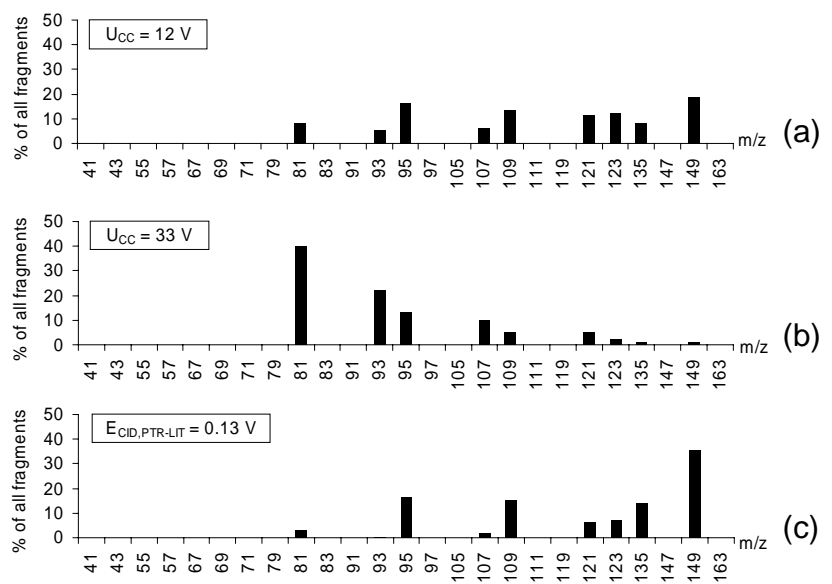

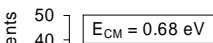

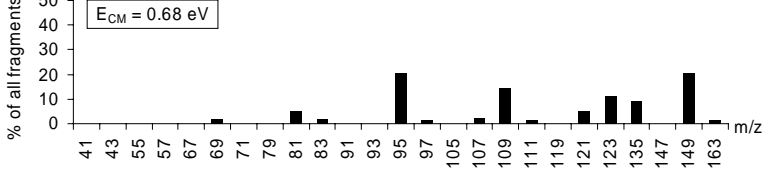

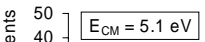

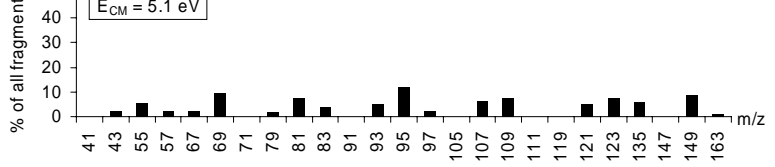

50
$E_{C M}=6.4 \mathrm{eV}$

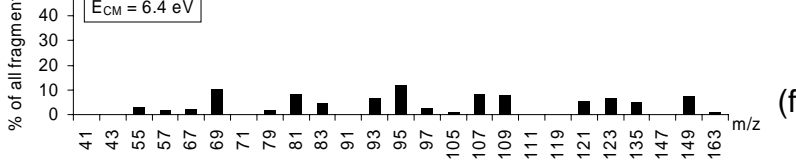

Fig. 4. Fragmentation patterns of protonated $\alpha$-humulene obtained by (a-c) Müller et al. (2009) (QqQ-MS and PTR-LIT) and by (d-f) FA-TMS at three different $E_{\mathrm{CM}}$. For FA-TMS, only fragments $>1 \%$ are shown. (a) $U_{\mathrm{cc}}=12 \mathrm{~V}$, (b) $U_{\mathrm{cc}}=33 \mathrm{~V}$, (c) $U_{\mathrm{CID}, \mathrm{PTR}-\mathrm{LIT}}=0.13 \mathrm{~V}$, (d) $E_{\mathrm{CM}}=0.68 \mathrm{eV}$, (e) $E_{\mathrm{CM}}=5.1 \mathrm{eV}$, and (f) $E_{\mathrm{CM}}=6.4 \mathrm{eV}$. The contribution of the precursor ion $\mathrm{I}_{p}$ in the fragmentation spectra, i.e. $I_{\mathrm{p}} /\left(I_{\mathrm{p}}+\Sigma I_{\mathrm{fi}}\right)$, equals $95.1,30.3$ and $29.9 \%$ in graphs (d), (e) and (f), respectively.

major fragment ions of $\mathrm{SQT}^{\bullet+}$ (maximum fragmentation fraction $>10 \%$ ) produced in the FA-TMS for $E_{\mathrm{CM}}<2 \mathrm{eV}$. Similarities also appear between EI and FA-TMS techniques: (i) for longifolene and isolongifolene, the major fragment ion is observed at $\mathrm{m} / \mathrm{z} 161$ for both EI and FA-TMS techniques, the maximum fragmentation fractions values in FA-TMS being $72 \%$ and $66 \%$ for these two respective SQTs (11-37\% for the other SQTs); (ii) for $\delta$-neoclovene, the major ion in the EI spectrum is observed at $m / z$ 120. In FA-TMS, this fragment ion has a maximum fragmentation fraction of $12 \%$ for this SQT, while this fraction varies between 2 and $6 \%$ for the other SQTs; (iii) the fragment ion at $\mathrm{m} / z$ 162, which is characteristic for the fragmentation pattern of ionized $\delta$ neoclovene in the FA-TMS instrument, represents $2 \%$ of the major peak in the EI spectrum (at $\mathrm{m} / \mathrm{z}, 120$ ), whereas this fraction is only between 2 and $24 \%$ for the other SQTs. In
Table 2. Fragment ions from the fragmentation of SQT molecular ions $(\mathrm{m} / \mathrm{z}, 204)$. In bold, $\mathrm{NO}^{+} / \mathrm{SQT}$ product ions observed in SIFTMS (Dhooghe et al., 2008). MFF = Maximum Fragmentation Fraction; $\mathrm{FF}=$ Fragmentation Fraction at $0.68 \mathrm{eV} . E_{\mathrm{CM}}(\mathrm{eV})$ indicates the range of $E_{\mathrm{CM}}$ where $\mathrm{MFF}$ is found.

\begin{tabular}{|c|c|c|c|c|}
\hline SQT & $m / z$ & MFF & $\begin{array}{l}E_{\mathrm{CM}} \\
(\mathrm{eV})\end{array}$ & $\begin{array}{c}\text { FF at } \\
0.68 \mathrm{eV}\end{array}$ \\
\hline \multirow[t]{4}{*}{$\alpha$-humulene } & 105 & 40 & $>6$ & \\
\hline & 122 & 10 & $<2$ & \\
\hline & 147 & 58 & $<2$ & 52 \\
\hline & 161 & 11 & $<3$ & 11 \\
\hline \multirow[t]{6}{*}{ Aromadendrene } & 94 & 10 & $<2$ & \\
\hline & 105 & 11 & $>6$ & \\
\hline & 119 & 13 & $>6$ & \\
\hline & 133 & 19 & $<2$ & \\
\hline & 161 & 31 & $<3$ & 31 \\
\hline & 189 & 12 & $<3$ & \\
\hline \multirow[t]{5}{*}{$\alpha$-cedrene } & 105 & 14 & $>6$ & \\
\hline & 108 & 16 & $<2$ & 16 \\
\hline & 119 & 37 & $>3$ & 25 \\
\hline & 147 & 15 & $<2$ & 15 \\
\hline & 161 & 19 & $<2$ & \\
\hline \multirow[t]{4}{*}{ longifolene } & 119 & 12 & $>6$ & \\
\hline & 133 & 17 & $>3$ & \\
\hline & 161 & 72 & $<2$ & 37 \\
\hline & 189 & 17 & $<2$ & 17 \\
\hline \multirow[t]{6}{*}{$\delta$-neoclovene } & 105 & 11 & $>6$ & \\
\hline & 119 & 18 & $>6$ & \\
\hline & 120 & 12 & $1.5-3.5$ & \\
\hline & 121 & 13 & $>4$ & \\
\hline & 161 & 12 & $<3$ & \\
\hline & 162 & 80 & $<2$ & 71 \\
\hline \multirow[t]{4}{*}{ Isolongifolene } & 119 & 12 & $>6$ & \\
\hline & 133 & 15 & $>6$ & \\
\hline & 147 & 25 & $<3$ & 24 \\
\hline & 161 & 66 & $<3$ & 66 \\
\hline \multirow[t]{7}{*}{$\beta$-caryophyllene } & 105 & 11 & $>6$ & \\
\hline & 133 & 20 & $>3$ & \\
\hline & 147 & 14 & $<1$ & 14 \\
\hline & 148 & 12 & $<1$ & \\
\hline & 161 & 37 & $<2$ & 32 \\
\hline & 175 & 10 & $<1$ & \\
\hline & 189 & 17 & $<2$ & 16 \\
\hline
\end{tabular}

general, however, it can be stated that CID of SQT ${ }^{\bullet+}$ in the FA-TMS results in much less fragmentation than impact of $70 \mathrm{eV}$ electrons onto SQTs. 

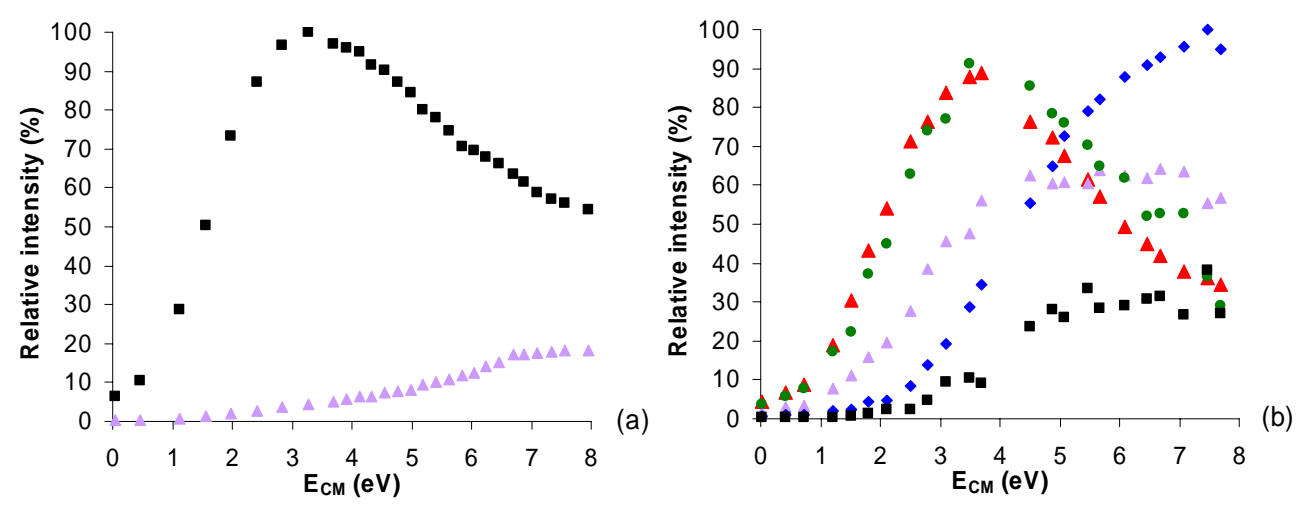

Fig. 5. Fragmentation patterns of (a) $\mathrm{m} / \mathrm{z} 147$ from $\alpha$-humulene and (b) $\mathrm{m} / \mathrm{z} 162$ from $\delta$-neoclovene as a function of collision energy. $(\boldsymbol{\square}) \mathrm{m} / \mathrm{z}, 105,(\boldsymbol{\Delta}) \mathrm{m} / \mathrm{z}$ 147, $(\diamond) \mathrm{m} / \mathrm{z}, 91,(\bullet) \mathrm{m} / \mathrm{z}, 106$ and $(\Delta)$ other fragment ions. Experimental error, not indicated on the graph for more clarity, varies between 0.5 and $29 \%$.

\subsection{Fragmentation of other CI fragment ions}

CID of product ions other than those at $m / z, 204$ and $m / z, 205$ formed in the FA with a sufficiently high contribution to the reactant ion/SQT product ion distribution was also investigated, as this may result in additional information or understanding of fragmentation patterns of SQT molecular ions and protonated SQT. The CI fragment ions at $m / z 149$ (for $\alpha$ humulene, aromadendrene, $\beta$-caryophyllene, $\delta$-neoclovene and longifolene), $m / z 135$ (for $\alpha$-humulene, aromadendrene, $\beta$-caryophyllene, $\delta$-neoclovene), $\mathrm{m} / z, 121$ (for $\alpha$-humulene and $\beta$-caryophyllene) and $m / z, 95$ (for $\alpha$-humulene, aromadendrene, $\beta$-caryophyllene, $\delta$-neoclovene and longifolene) were produced in the FA with $\mathrm{H}_{3} \mathrm{O}^{+}$as reagent ions and were introduced in the collision cell. CI fragment ions at $\mathrm{m} / \mathrm{z}, 109$ and $\mathrm{m} / \mathrm{z}, 123$ were not considered in our study because of an isobaric interference present in the background.

CID of CI fragment ions of fixed $\mathrm{m} / z$ ratio do not result in specific fragment ion $m / z$ values for the SQT studied. Identical CID fragmentation patterns were found, albeit with different fragment ion intensities for the different SQT species. Therefore, the fragmentation study of CI fragment ions does not really provide supplementary information for the selective detection of SQTs. With the exception of fragment ions at $m / z 39,53,80,89$ and 120, all fragment ions (with a maximum fragmentation fraction $>5 \%$ ) resulting from the fragmentation of $\mathrm{CI}$ fragment ions are also produced from the fragmentation of protonated SQT $(\mathrm{m} / \mathrm{z}, 29, \mathrm{~m} / \mathrm{z}, 41, \mathrm{~m} / \mathrm{z}, 43$, $\mathrm{m} / \mathrm{z} 55, \mathrm{~m} / \mathrm{z} 67, \mathrm{~m} / \mathrm{z} 69, \mathrm{~m} / \mathrm{z} 77, \mathrm{~m} / \mathrm{z} 79, \mathrm{~m} / \mathrm{z} 81, \mathrm{~m} / \mathrm{z} 91, \mathrm{~m} / \mathrm{z} 93$, $\mathrm{m} / \mathrm{z}, 105, \mathrm{~m} / \mathrm{z}, 107, \mathrm{~m} / \mathrm{z} 119$ and $\mathrm{m} / \mathrm{z}, 121)$. It can be remarked that ions at $\mathrm{m} / \mathrm{z} 89$ are not included in the six families (Table 1) and that ions at $m / z 80$ and 120 are formed, despite the fact that it is expected to be thermodynamically improbable $\left(\mathrm{EE}^{+} \rightarrow \mathrm{OE}^{\bullet+}\right)$.

The CI fragment ions at $m / z 147$ ( $\alpha$-humulene), $m / z, 148$ ( $\beta$-caryophyllene), $m / z 25161$ ( $\beta$-caryophyllene), $m / z 162$ ( $\delta$-neoclovene), $m / z 176(\beta$-caryophyllene) and $m / z \quad 189$
( $\beta$-caryophyllene) were produced in the $\mathrm{FA}$ with $\mathrm{NO}^{+}$as reagent ions and were subjected to fragmentation in the collision cell of the FA-TMS. The fragmentation patterns of ions at $m / z 147$ ( $\alpha$-humulene) and $m / z, 162$ ( $\delta$-neoclovene) as a function of the collision energy are presented in Fig. 5a and $b$, respectively. These examples have been chosen because the fragmentation of these two ions produces only a limited number of fragment ions, implying clear appearance curves. The ions at $\mathrm{m} / z 147$ mainly fragment into ions at $\mathrm{m} / \mathrm{z} 105$ (maximum fragmentation fraction $=98 \%$ at about $2 \mathrm{eV})$. Other fragment ions appear at higher collision energies (Fig. 5a). The link between the ions at $m / z 147$ and $\mathrm{m} / \mathrm{z} 105$ may explain why ions at $\mathrm{m} / \mathrm{z} 105$ are observed at a higher maximum fragmentation fraction for the fragmentation of the $\alpha$-humulene molecular ion (40\%, Table 2 ) than for the other SQTs $(<14 \%$, Table 2$)$. The fragmentation of ions at $m / z, 162$ ( $\delta$-neoclovene) produces fragment ions at $\mathrm{m} / z 147$ and $\mathrm{m} / \mathrm{z} 106$ following a bell-shaped appearance curve characterized by a maximum intensity at about $3.5 \mathrm{eV}$ (Fig. 5b). The formation of the fragment ions at $\mathrm{m} / \mathrm{z}, 91$ and $\mathrm{m} / \mathrm{z} 105$ requires more energy since their maximum intensity is reached for collision energies $>6 \mathrm{eV}$. The fragmentation of $\mathrm{NO}^{+} \mathrm{CI}$ fragment ions from $\beta$-caryophyllene produces lots of ions with maximum fragmentation fractions below $38 \%$. The fragmentation patterns are detailed in Table 3.

The CI product ions at $m / z 234\left(\mathrm{C}_{15} \mathrm{H}_{24} \cdot \mathrm{NO}\right)^{+}$, resulting from the association reaction between $\mathrm{NO}^{+}$and longifolene in the FA, as it was already observed in SIFT-MS experiments (Dhooghe et al., 2008), were sufficiently stable to be introduced in the collision cell of the TMS for fragmentation by collision with Ar. At very low collision energy (close to $0 \mathrm{eV}$ ), the fragmentation of the adduct produces ions at $m / z 204\left(\mathrm{C}_{15} \mathrm{H}_{24}^{\bullet+}\right)$. The fragmentation process does not correspond to the reverse reaction of association taking place in the FA. This result proves that the charge, shared in the complex to assure its stability, is preferentially transferred to the sesquiterpene to form the fragment ions at $m / z 204$ after the 
Table 3. Fragment ions with maximum fragmentation fraction $>10 \%$ from the fragmentation of CI fragment ions from the reaction between $\beta$-caryophyllene and $\mathrm{NO}^{+}$.

\begin{tabular}{lrrrrrrr}
\hline $\begin{array}{l}\text { Precursor } \\
m / z\end{array}$ & $\begin{array}{r}\text { Fragments } \\
m / z\end{array}$ & $\begin{array}{r}\text { MFF } \\
(\%)\end{array}$ & $\begin{array}{r}E_{\mathrm{CM}} \\
(\mathrm{eV})\end{array}$ & $\begin{array}{r}\text { Precursor } \\
m / z\end{array}$ & $\begin{array}{r}\text { Fragments } \\
m / z\end{array}$ & $\begin{array}{r}\text { MFF } \\
(\%)\end{array}$ & $\begin{array}{r}E_{\mathrm{CM}} \\
(\mathrm{eV})\end{array}$ \\
\hline 148 & 133 & 38 & 3 & 176 & 161 & 37 & $>4$ \\
& 119 & 11 & 4 & & 134 & 14 & $>4$ \\
& 106 & 24 & 3 & & 133 & 12 & $>4$ \\
& 105 & 15 & $>5$ & & 120 & 14 & $>4$ \\
& 91 & 26 & 6 & & 119 & 20 & $>4$ \\
& & & & & 105 & 16 & $>4$ \\
\hline 161 & 133 & 11 & 3 & 189 & 147 & 11 & 4 \\
& 119 & 23 & 4 & & 133 & 19 & 4 \\
& 105 & 32 & 4 & & 119 & 14 & 4 \\
& 91 & 16 & $>6$ & & 105 & 12 & $>6$ \\
& 81 & 11 & 4 & & 95 & 15 & 4 \\
\hline
\end{tabular}

collision process. The capability of longifolene to carry the charge can be explained by the lower ionization energy of longifolene (8.55 eV; Novak et al., 2001) compared to $\mathrm{NO}^{\bullet}$ $(9.25 \mathrm{eV})$.

\subsection{Selective detection of SQTs}

The fragmentation patterns of the different protonated SQTs only differ by variations in the fragment ion abundances. Selected ratios at different collision energies are presented for the seven SQTs in Fig. 6. Müller et al. (2009) used the intensity ratios $I_{149} / I_{121}$ and $I_{93} / I_{81}$ for the distinction between $\alpha$-humulene and farnesene. The first one can be used to distinguish all the SQTs studied in our work, whereas the second one is not appropriate to differentiate them, especially due to large uncertainties on the ratios. The ratios $I_{69} / I_{123}$, $I_{121} / I_{123}$ and $I_{83} / I_{135}$ allow to discriminate isolongifolene, $\alpha$-cedrene and aromadendrene, respectively, from the other SQTs.

The fragmentation patterns of SQT molecular ions provide powerful information for the selective detection of SQTs and even their quantification. At well-chosen collision energies, some tracers can be found. A fragment ion is considered as a tracer of a specific SQT if its fragmentation fraction is at least ten times higher than for the other SQTs studied. It is the case for ions at $m / z, 119$ at $0.7 \mathrm{eV}$ for $\alpha$-cedrene, $m / z, 162$ at $0.7 \mathrm{eV}$ and $m / z 83$ at $6.1 \mathrm{eV}$ for $\delta$-neoclovene, $\mathrm{m} / \mathrm{z}, 137$ at $2.5 \mathrm{eV}$ for longifolene and $\mathrm{m} / \mathrm{z}, 131$ at $0.7 \mathrm{eV}$ for $\alpha$-humulene (Table 4 ). Through this method, an independent quantification of these four SQTs present in a mixture can be envisaged. No tracers were found for the other three SQTs when considering the set of seven SQTs studied. However, when reducing this set, specific tracer fragment ions could still be found for aromadendrene at $\mathrm{m} / \mathrm{z} 120$ at $4.8 \mathrm{eV}$, isolongifolene at $\mathrm{m} / \mathrm{z} 175$ at $4.5 \mathrm{eV}$ and $\beta$-caryophyllene at $m / z 133$ at $3.2 \mathrm{eV}$ (Table 4).
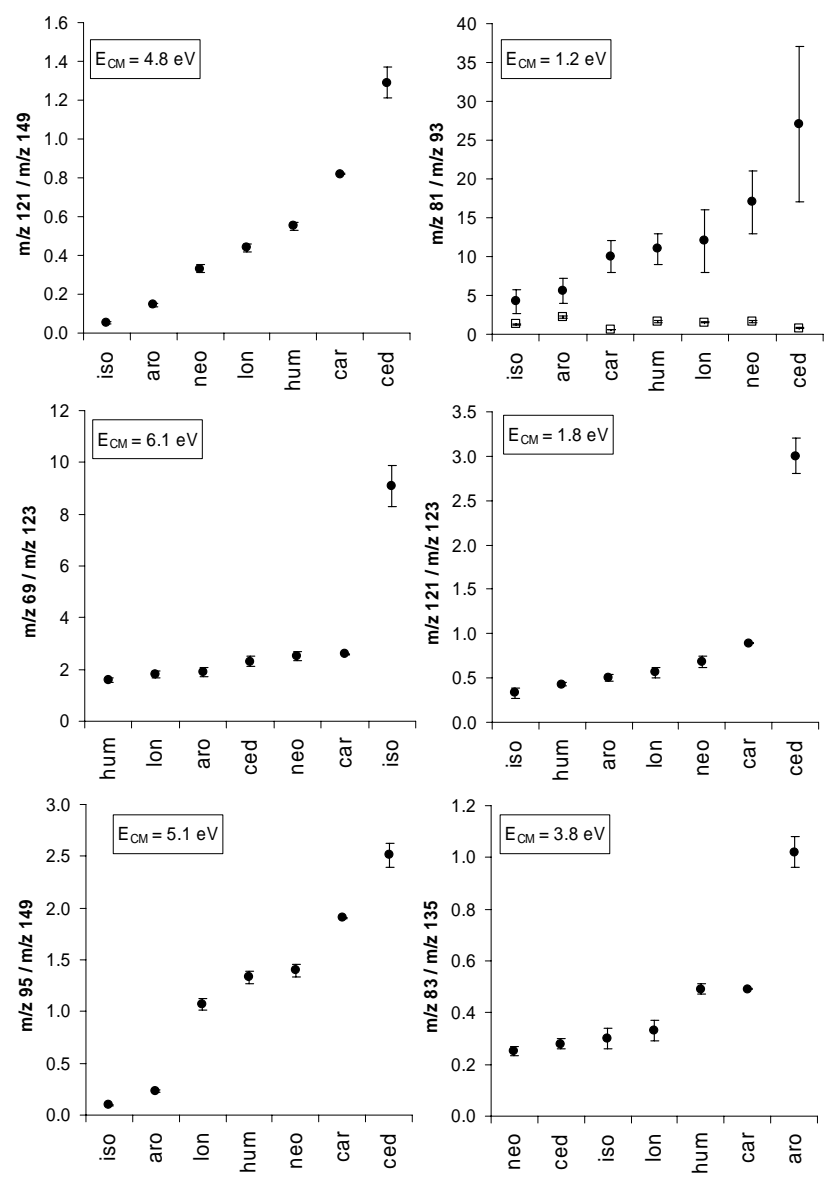

Fig. 6. Selected fragment ion intensity ratios from the fragmentation of protonated SQT. Error bars correspond to $2 \sigma$. 
Table 4. Fragmentation fractions (FF) for $\mathrm{SQT}^{+}$fragment ions. Values shown in bold are associated to SQTs for which the corresponding fragment ion at the specified $E_{\mathrm{CM}}$ value can be considered as a tracer when analyzing mixtures containing the seven SQTs studied. Tracer fragment ions for aromadendrene, $\beta$-caryophyllene and isolongifolene were only found for restricted sets of SQTs, which do not comprise those compounds for which the FF value is shown against a grey background. Results are not corrected for mass discrimination effects. Also shown is the estimated sensitivity and LOD (based on a $20 \mathrm{~s}$ dwell time) of a hypothetical PTR-SRI-TMS instrument for the detection of individual SQTs (associated to FF values in bold) by monitoring the corresponding tracer fragment ions. The estimated sensitivity and LOD values are given for two distinct values of the RF frequency $(2.1$ and $2.9 \mathrm{MHz})$ of the voltages on the collision cell octupole rods (see text).

\begin{tabular}{|c|c|c|c|c|c|c|c|c|c|c|}
\hline SQT & $\begin{array}{l}m / z 162 \\
0.68 \mathrm{eV}\end{array}$ & $\begin{array}{l}m / z 119 \\
0.68 \mathrm{eV}\end{array}$ & $\begin{array}{l}m / z 131 \\
0.68 \mathrm{eV}\end{array}$ & $\begin{array}{l}m / z 137 \\
3.2 \mathrm{eV}\end{array}$ & $\begin{array}{l}m / z 83 \\
6.1 \mathrm{eV}\end{array}$ & $\begin{array}{l}m / z 147 \\
2.8 \mathrm{eV}\end{array}$ & $\begin{array}{l}m / z 133 \\
3.2 \mathrm{eV}\end{array}$ & $\begin{array}{l}m / z 175 \\
4.5 \mathrm{eV}\end{array}$ & $\begin{array}{l}m / z 120 \\
4.8 \mathrm{eV}\end{array}$ & $\begin{array}{l}\% \mathrm{PID} \\
m / z 204^{*}\end{array}$ \\
\hline Aromadendrene & $3.9 \pm 0.2$ & $2.4 \pm 0.2$ & N.O. & N.O. & $0.49 \pm 0.05$ & $5.0 \pm 0.2$ & $6.4 \pm 0.2$ & $1.6 \pm 0.1$ & $5.0 \pm 0.2$ & 94 \\
\hline$\alpha$-cedrene & N.O. & $24.5 \pm 0.8$ & $0.24 \pm 0.04$ & N.O. & $0.40 \pm 0.03$ & $9.7 \pm 0.2$ & $1.27 \pm 0.04$ & $0.91 \pm 0.02$ & $2.6 \pm 0.1$ & 98 \\
\hline longifolene & N.O. & $0.57 \pm 0.04$ & N.O. & $4.7 \pm 0.1$ & N.O. & $3.6 \pm 0.1$ & $15.8 \pm 0.3$ & $2.6 \pm 0.1$ & $2.4 \pm 0.1$ & 93 \\
\hline$\delta$-neoclovene & $71 \pm 1$ & $0.97 \pm 0.05$ & N.O. & N.O. & $9.3 \pm 0.2$ & $3.3 \pm 0.1$ & $2.0 \pm 0.1$ & $0.64 \pm 0.03$ & $4.9 \pm 0.1$ & 94 \\
\hline isolongifolene & N.O. & $1.3 \pm 0.2$ & N.O. & N.O. & $0.44 \pm 0.04$ & $24.2 \pm 0.4$ & $3.7 \pm 0.1$ & $9.8 \pm 0.2$ & $0.28 \pm 0.02$ & 99 \\
\hline$\alpha$-humulene & $0.96 \pm 0.08$ & $1.7 \pm 0.1$ & $3.8 \pm 0.2$ & N.O. & $0.17 \pm 0.02$ & $44.2 \pm 0.7$ & $1.6 \pm 0.1$ & $0.80 \pm 0.04$ & $1.5 \pm 0.1$ & 77 \\
\hline$\beta$-caryophyllene & N.O. & $0.47 \pm 0.05$ & N.O. & N.O. & $0.33 \pm 0.03$ & $6.3 \pm 0.2$ & $16.1 \pm 0.4$ & $3.4 \pm 0.1$ & $3.1 \pm 0.1$ & 59 \\
\hline$S_{\text {est, } 2.1 \mathrm{MHz}}(\mathrm{cps} / \mathrm{ppbv})$ & 3.52 & 0.24 & 0.03 & 0.26 & 1.22 & 1.97 & 0.48 & 0.67 & 0.32 & \\
\hline $\mathrm{LOD}_{\mathrm{est}}, 2.1 \mathrm{MHz}$ (pptv) & 43 & 630 & 5600 & 580 & 120 & 76 & 320 & 240 & 470 & \\
\hline$S_{\text {est, } 2.9 \mathrm{MHz}}(\mathrm{cps} / \mathrm{ppbv})$ & 47.9 & 2.07 & 0.27 & 2.75 & 13.1 & 23.4 & 4.89 & 10.0 & 2.77 & \\
\hline $\mathrm{LOD}_{\text {est, }} 2.9 \mathrm{MHz}$ (pptv) & 3 & 47 & 410 & 43 & 9 & 6 & 23 & 18 & 35 & \\
\hline
\end{tabular}

* Relative contribution $\%$ of the $\mathrm{SQT}^{+}$ion in the $\mathrm{NO}^{+} / \mathrm{SQT}$ product ion distribution as obtained from SIFT-MS experiments (Dhooghe et al., 2008)

N.O.: fragment ion not observed.

Although the fragment ion at $\mathrm{m} / \mathrm{z} 131$ (at $0.7 \mathrm{eV}$ ) is a tracer for $\alpha$-humulene within the set of the seven SQTs studied, its applicability for sensitive detection is restricted by its low fragmentation fraction and the low CID efficiency of the SQT molecular ion at $0.7 \mathrm{eV}$. A different fragment ion, allowing more sensitive detection of $\alpha$-humulene albeit within a reduced set of SQTs, was found at $\mathrm{m} / \mathrm{z} 147$ at $2.8 \mathrm{eV}$.

\subsection{Considerations about the sensitivity of CI/MS/MS using $\mathrm{NO}^{+}$reagent ions for selective sesquiterpene detection}

In its present configuration the laboratory FA-TMS instrument is not sufficiently sensitive for selective detection of sesquiterpenes at low concentrations. This lack of sensitivity is mainly due to a limited reagent ion production and inefficient ion optics for guiding the ions from the sampling orifice to the ion deflector in front of the QoQ probe. In order to allow selective detection of sesquiterpenes in ambient conditions, the instrument might well benefit from a replacement of the FA reactor by a drift tube reactor equipped with a highly efficient hollow cathode $\mathrm{NO}^{+}$ion source as in the commercial PTR+SRI-MS instrument (Jordan et al., 2009). In order to evaluate the usefulness of the CI/MS/MS technique for ambient selective sesquiterpene detection, we estimated the sensitivity and detection limit (LOD) of such a hypothetical instrument in which the quadrupole mass filter of a PTR+SRI-MS was replaced by the QoQ tandem mass spectrometer probe. Sensitivity values (expressed in counts per second per ppbv) were calculated for the different sesquiterpenes based on their CID tracer fragment ion intensities.
These calculations were based on realistic values for the production and transmission of sesquiterpene molecular ions in a PTR+SRI-MS instrument in typical $\mathrm{NO}^{+}$operating conditions $\left(E / N=100 \mathrm{Td}, 40 \mathrm{Mcps}^{+} \mathrm{NO}^{+}, T_{\text {reactor }}=333 \mathrm{~K}\right)$ and on experimental values of $E_{\mathrm{CID}}$ and the fragmentation fraction $(\mathrm{FF})$ of the tracer fragment ions at the specified $E_{\mathrm{CM}}$ values. The contribution of the sesquiterpene molecular ions to the $\mathrm{NO}^{+}$/sesquiterpene product ion distribution in the PTR+SRI reactor was considered to be similar as in SIFT conditions, as was the case for protonated sesquiterpenes in the $\mathrm{H}_{3} \mathrm{O}^{+}$ $\left(\mathrm{H}_{2} \mathrm{O}\right)_{n}$ /sesquiterpene product ion distribution (Demarcke et al., 2009) for an $E / N$ of $100 \mathrm{Td}$. Tests performed on the TMS probe by the manufacturer (Extrel CMS, Pittsburgh, USA) showed a transmission loss of about $80 \%$ for ions at $m / z, 219$ (an EI fragment of perfluorotributylamine) when switching from a single quadrupole configuration to a QoQ configuration without introducing collision gas in the octupole collision cell. Given the proximity of this $\mathrm{m} / \mathrm{z}$ ratio to the one of the sesquiterpene molecular ion, a similar transmission loss is taken into account for the latter ion species. The tracer fragment ion signal in the presence of collision gas will only be a fraction, equal to $E_{\mathrm{CID}} \times \mathrm{FF}$, of the ion signal at $m / z 204$ in the absence of collision gas. The unfavourable effects of reduced ion transmission in the tandem probe and incomplete fragmentation of the precursor ions in the collision cell ( $E_{\mathrm{f}}$ varies between 5 and $75 \%$ ) on the detection limit of the individual sesquiterpenes are partly compensated by the very low TMS background signal at the $m / z$ values of the tracer fragment ions (no contributions from ionization of interfering compounds in the PTR+SRI reactor), which is lower than $0.05 \mathrm{cps}$ for an integration time of $20 \mathrm{~s}$, resulting 
in acceptable detection limits for most sesquiterpenes. Estimations of the sensitivity and LOD (for a $20 \mathrm{~s}$ dwell time) of the hypothetical instrument for detection of individual sesquiterpenes based on tracer fragment ions at specific $E_{\mathrm{CM}}$ conditions are given in Table 4. These LOD values can be considered as conservative upper limits as the upper limit for the background signal ( $0.05 \mathrm{cps}$ for a $20 \mathrm{~s}$ integration period) was taken as the standard deviation on the background signal. Presently the octupole guide in the collision cell of the tandem probe is operated at an RF-frequency of $2.1 \mathrm{MHz}$. Performance tests on the QoQ probe by the manufacturer (Extrel CMS, Pittsburgh, USA) have shown that increasing this frequency to $2.9 \mathrm{MHz}$ results in a significant increase in the transmission and fragmentation efficiencies (K. Kuchta and J. Wei, Extrel Application note GA-380C). Estimated sensitivities and detection limits taking into account the performance of a $2.9 \mathrm{MHz}$ octupole guide are given in Table 4 as well.

\section{Conclusions}

Recent developments in the field of chemical ionization mass spectrometry reveal the need for selective and highly sensitive on-line techniques for detection and quantification of isobaric/isomeric BVOCs. The results of this work show that a Flowing Afterglow reactor coupled to a Tandem Mass Spectrometer (FA-TMS) can be a useful instrument to distinguish SQTs, a particular class of BVOCs of high interest to the atmospheric chemistry community.

A first part of our study focused on chemical ionization of seven SQTs using $\mathrm{H}_{3} \mathrm{O}^{+}$reactant ions and the subsequent fragmentation of the protonated SQT in the collision cell of the tandem mass spectrometer. No specific fragment ion tracers were found for the different SQTs, but large differences in fragment ion intensity ratios were sometimes noticed between SQTs. Moreover, the measurements showed that it is often useful to look at fragment ion ratios over an extended collision energy range $(0.6-8 \mathrm{eV}$ in our case). Identification of the seven SQTs studied can for instance be envisaged from the ratio $I_{121} / I_{149}$, and the ratios $I_{69} / I_{123}, I_{121} / I_{123}$ and $I_{83} / I_{135}$ were found to be much larger for isolongifolene, $\alpha$-cedrene and aromadendrene, respectively. However, in agreement with Müller et al. (2009), who recently applied this method in a PTRLIT and in a QqQ-MS provided with a Townsend Discharge ion source for two SQT species, we have to conclude that on-line identification and quantification of individual SQT in a mixture containing more than one SQT by MS/MS of protonated SQT will be extremely difficult.

In a second part of the present study, the use of $\mathrm{NO}^{+}$reactant ions for chemical ionization of SQTs, followed by CID of the resulting $\mathrm{SQT}^{\bullet+}$ ions was investigated. This methodology looks far more promising, as it resulted in fragment ion tracers for four out of the seven SQTs studied: $\alpha$-cedrene, $\delta$-neoclovene, longifolene and $\alpha$-humulene, and this opens a way to selective on-line quantification of SQTs in more complex matrices. Of course these measurements will still have to be accompanied by a powerful off-line technique for SQTs identification, such as GC-MS, and the other SQT (not among the seven SQTs studied) will have to be introduced individually in the on-line CIMS instrument in search for tracers.

The present study has focused on selective detection of SQT isomers and not on their quantification. In its present state, the FA-TMS is not able to quantify SQTs in air at mixing ratios that are typical for field studies (some pptv). In order to drastically enhance the detection sensitivity, future work will deal with the replacement of the FA reactor by a drift tube reactor coupled to a hollow cathode discharge ion source for the production of large concentrations of $\mathrm{NO}^{+}$reactant ions.

Acknowledgements. The authors gratefully acknowledge the financial support of the Belgian Federal Science Policy (research projects \#MO/35/022 and \#MO/35/026) and of the Institute for the Promotion of Innovation through Science and Technology in Flanders (IWT-Vlaanderen). They also thank David Smith for providing interesting comments on some ion chemistry related aspects of this work.

Edited by: E. C. Apel

\section{References}

Atkinson, R. and Arey, J.: Gas-phase tropospheric chemistry of biogenic volatile organic compounds: a review, Atmos. Environ., 37, 197-219, 2003.

Blake, R. S., Whyte, C., Hughes, C. O., Ellis, A. M., and Monks, P. S.: Demonstration of Proton-Transfer Reaction Time-of-Flight Mass Spectrometry for Real-Time Analysis of Trace Volatile Organic Compounds, Anal. Chem., 76, 3841-3845, 2004.

Blake, R. S., Wyche, K. P., Ellis, A. M., and Monks, P. S.: Chemical ionization reaction time-of-flight mass spectrometry: Multireagent analysis for determination of trace gas composition, Int. J. Mass Spectrom., 254, 85-93, 2006.

Blake, R. S., Monks, P. S., and Ellis, A. M.: Proton-Transfer Reaction Mass Spectrometry, Chem. Rev., 109, 861-896, 2009.

Bonn, B. and Moortgat, K.: Sesquiterpene ozonolysis: Origin of atmospheric new particle formation from biogenic hydrocarbons, Geophys. Res. Lett., 30, 1585, doi:10.1029/2003GL017000, 2003.

Bouvier-Brown, N. C., Goldstein, A. H., Gilman, J. B., Kuster, W. C., and de Gouw, J. A.: In-situ ambient quantification of monoterpenes, sesquiterpenes, and related oxygenated compounds during BEARPEX 2007: implications for gas- and particle-phase chemistry, Atmos. Chem. Phys., 9, 5505-5518, doi:10.5194/acp-9-5505-2009, 2009a.

Bouvier-Brown, R. C., Holzinger, R., Palitzsch, K., and Goldstein, H.: Large emissions of sesquiterpenes and methyl chavicol quantified from branch enclosure measurements, Atmos. Environ., 43, 389-401, 2009b. 
Boy, M., Karl, T., Turnipseed, A., Mauldin, R. L., Kosciuch, E., Greenberg, J., Rathbone, J., Smith, J., Held, A., Barsanti, K., Wehner, B., Bauer, S., Wiedensohler, A., Bonn, B., Kulmala, M., and Guenther, A.: New particle formation in the Front Range of the Colorado Rocky Mountains, Atmos. Chem. Phys., 8, 15771590, doi:10.5194/acp-8-1577-2008, 2008.

Canosa-Mas, C. E., King, M. D., Scarr, P. J., Thompson, K. C., and Wayne, R. P.: An experimental study of the gas-phase reactions of the $\mathrm{NO}_{3}$ radical with three sesquiterpenes: isolongifolene, alloisolongifolene, and [small alpha]-neoclovene, Phys. Chem. Chem. Phys., 1, 2929-2933, 1999.

De Hoffmann, E. and Stroobant, V.: Mass spectrometry - Principles and applications, 3rd edition, John Wiley \& sons, The Atrium, Southern Gate, Chichester, West Sussex, England, 2007.

Demarcke, M., Amelynck, C., Schoon, N., Dhooghe, F., Van Langenhove, H., and Dewulf, J.: Laboratory studies in support of the detection of sesquiterpenes by proton-transfer-reaction-massspectrometry, Int. J. Mass Spectrom., 279, 156-162, 2009.

Dhooghe, F., Amelynck, C., Schoon, N., Debie, E., Bultinck, P., and Vanhaecke, F.: A selected ion flow tube study of the reactions of $\mathrm{H}_{3} \mathrm{O}^{+}, \mathrm{NO}^{+}$and $\mathrm{O}_{2}^{+}$with a series of sesquiterpenes, Int. J. Mass Spectrom., 272, 137-148, 2008.

Duhl, T. R., Helmig, D., and Guenther, A.: Sesquiterpene emissions from vegetation: a review, Biogeosciences, 5, 761-777, doi:10.5194/bg-5-761-2008, 2008.

Ezra, D., Jasper, J., Rogers, T., Knighton, B., Grimsrud, E., and Strobel, G.: Proton transfer reaction-mass spectrometry as a technique to measure volatile emissions of Muscodor albus, Plant Sci., 166, 1471-1477, 2004.

Graus, M., Müller, M., and Hansel, A.: High resolution PTR-TOF: quantification and formula confirmation of VOC in real time, J. Am. Soc. Mass Spectrom., 21, 1037-1044, 2010.

Helmig, D. and Arey, J.: Organic chemicals in the air at Whitaker's Forest/Sierra Nevada Mountains, California, Sci. Total Environ., 112, 233-250, 1992.

Helmig, D., Revermann, T., Pollmann, J., Kaltschmidt, O., Jiménez Hernández, A., Bocquet, F., and David, D.: Calibration system and analytical considerations for quantitative sesquiterpene measurements in air, J. Chromatogr. A, 1002, 193-211, 2003.

Holopainen, J. K. and Gershenzon, J.: Multiple stress factors and the emission of plant VOCs, Trends Plant Sci., 15, 176-184, 2010.

Ibrahim, Y. M., Prior, D. C., Baker, E. S., Smith, R. D., and Belov, M. E.: Characterization of an ion mobility-multiplexed collision-induced dissociation-tandem time-of-flight mass spectrometry approach, Int. J. Mass Spectrom., 293, 34-44, 2010.

Jordan, A., Haidacher, S., Hanel, G., Hartungen, E., Herbig, J., Märk, L., Schottkowsky, R., Seehauser, H., Sulzer, P., and Märk, T. D.: An online ultra-high sensitivity proton-transfer-reaction mass-spectrometer combined with switchable reagent ion capability (PTR+SRI-MS), Int. J. Mass Spectrom., 286, 32-38, 2009.

Jordan, A., Haidacher, S., Hanel, G., Hartungen, E., Märk, L., Seehauser, H., Schottkowsky, R., Sulzer, P., and Märk, T. D.: A high resolution and high sensitivity time-of-flight protontransfer-reaction mass spectrometer (PTR-TOF-MS), Int. J. Mass Spectrom., 286, 122-128, 2009.

Kesselmeier, J. and Staudt, M.: Biogenic Volatile Organic Compounds (VOC): an overview on emission, physiology and ecology, J. Atmos. Chem., 33, 23-88, 1999.
Kim, S., Karl, T., Helmig, D., Daly, R., Rasmussen, R., and Guenther, A.: Measurement of atmospheric sesquiterpenes by proton transfer reaction-mass spectrometry (PTR-MS), Atmos. Meas. Tech., 2, 99-112, doi:10.5194/amt-2-99-2009, 2009.

Knighton, B., Fortner, E. C., Herndon, S. C., Wood, E. C., and Miake-Lye, R. C.: Adaptation of a proton transfer reaction mass spectrometer instrument to employ $\mathrm{NO}^{+}$as reagent ion for the detection of 1,3-butadiene in the ambient atmosphere, Rapid Commun. Mass Sp., 23, 3301-3308, 2009.

Lee, A., Goldstein, A. H., Keywood, M. D., Gao, S., Varutbangkul, V., Bahreini, R., Ng, N. L., Flagan, R. C., and Seinfeld, J. H.: Gas-phase products and secondary aerosol yields from the ozonolysis of 16 different terpenes, J. Geophys. Res., 111, D17305, doi:10.1029/2005JD006437, 2006a.

Lee, A., Goldstein, A. H., Keywood, M. D., Gao, S., Varutbangkul, V., Bahreini, R., Ng, N. L., Flagan, R. C., and Seinfeld, J. H.: Gas-phase products and secondary aerosol yields from the ozonolysis of ten different terpenes, J. Geophys. Res., 111, D07302, doi:10.1029/2005JD006437, 2006b.

Loreto, F. and Schnitzler, J.-P.: Abiotic stresses and induced BVOCs, Trends Plant Sci., 15, 154-166, 2010.

Müller, M., Mielke, L. H., Breitenlechner, M., McLuckey, S. A., Shepson, P. B., Wisthaler, A., and Hansel, A.: MS/MS studies for the selective detection of isomeric biogenic VOCs using a Townsend Discharge Triple Quadrupole Tandem MS and a PTR-Linear Ion Trap MS, Atmos. Meas. Tech., 2, 703-712, doi:10.5194/amt-2-703-2009, 2009.

Muntean, F. and Armentrout, P. B.: Guided ion beam study of collision-induced dissociation dynamics: integral and differential cross sections, J Chem. Phys., 115, 1213-1228, 2001.

Novak, I., Kovac, B., and Kovacevic, G.: Electronic structure of terpenoids, J. Org. Chem., 66, 4728-4731, 2001.

Paré, P. W. and Tumlinson, J. H.: De Novo Biosynthesis of Volatiles Induced by Insect Herbivory in Cotton Plants, Plant Physiol., 114, 1161-1167, 1997.

Paré, P. W. and Tumlinson, J. H.: Plant volatiles as a defense against insect herbivores, Plant Physiol., 121, 135-331, 1999.

Peñuelas, J. and Staudt, M.: BVOCs and global change, Trends Plant Sci., 15, 133-144, 2010.

Pichersky, E. and Gershenzon, J.: The formation and function of plant volatiles: perfumes for pollinator attraction and defense, Curr. Opin. Plant Biol., 5, 237-243, 2002.

Rimetz-Planchon, J., Schoon, N., Amelynck, C., and Dhooghes, F.: Collision induced dissociation in a flowing afterglow-tandem mass spectrometer for the selective detection of $\mathrm{C}_{5}$ unsaturated alcohols and isoprene, Int. J. Mass Spectrom., 289, 30-38, 2010.

Smith, D. and Špaňel, P.: Selected ion flow tube mass spectrometry (SIFT-MS) for on-line trace gas analysis, Mass Spectrom. Rev., 24, 661-700, 2005.

Špaňel, P. and Smith, D.: SIFT studies of the reactions of $\mathrm{H}_{3} \mathrm{O}^{+}$, $\mathrm{NO}^{+}$and $\mathrm{O}_{2}^{+}$with a series of alcohols, Int. J. Mass Spectrom., 167-168, 375-388, 1997.

Špaňel, P. and Smith, D.: Selected ion flow tube studies of the reactions of $\mathrm{H}_{3} \mathrm{O}^{+}, \mathrm{NO}^{+}$, and $\mathrm{O}_{2}^{+}$with several aromatic and aliphatic hydrocarbons, Int. J. Mass Spectrom., 181, 1-10, 1998.

Špaňel, P., Ji, Y., and Smith, D.: SIFT studies of the reactions of $\mathrm{H}_{3} \mathrm{O}^{+}, \mathrm{NO}^{+}$and $\mathrm{O}_{2}^{+}$with a series of aldehydes and ketones, Int. J. Mass Spectrom., 165-166, 25-37, 1997. 
Thomson, B. A., Douglas, D. J., Corr, J. J., Hager, J. W., and Jolliffe, C. L.: Improved Collisionally Activated Dissociation Efficiency and Mass Resolution on a Triple Quadrupole Mass Spectrometer System, Anal. Chem., 67, 1696-1704, 1995.

Wyche, K. P., Blake, R. S., Willis, K. A., Monks, P. S., and Ellis, A. M.: Differentiation of isobaric compounds using chemical ionization reaction mass spectrometry, Rapid Commun. Mass Sp., 19, 3356-3362, 2005.
Yost, R. A., Enke, C. G., McGilvery, D. C., Smith, D., and Morrison, J. D.: High efficiency collision-induced dissociation in an RF-only quadrupole, Int. J. Mass Spectrom., 30, 127-136, 1979. 